\title{
METODOLOGIA DE BENCHMARKING PARA A PRODUÇÃO MAIS LIMPA E PRÁTICÁS SUSTENTÁVEIS: UM ESTUDO NO SETOR DE PVC
}

\author{
Paola Andrea de Antonio Boada, Msc. em Eng. Mecânica (UFSC); \\ Orientador:Prof. João Carlos Espindola Ferreira, Ph.D. (UFSC).
}

\section{INTRODUÇÃO}

O presente trabalho propõe o desdobramento de uma metodologia aplicada no setor de PVC no estado de SC.

O Poli (Cloreto de Vinila) ou PVC é um material plástico versátil, com a segunda colocação mundial dentre os termoplásticos. Sua cadeia produtiva é composta por indústrias de primeira, segunda e terceira gerações, as quais, dependendo das caraterísticas desejadas do produto final, modificam sua formulação, estrutura e processos para a obtenção do produto final, que é altamente diversificado, incluindo desde sistemas de coleta de água, janelas, conexões, fios, cabos e esquadrias, até cateteres e sacos de sangue e soro.

Seu impacto ao meio ambiente tem sido estudado nos últimos anos, por questões relativas à saúde humana, emissões, resíduos gerados e gestão sustentável de produtos e processos, conduzindo consequentemente a uma postura mais participativa na gestão das empresas envolvidas em todos os segmentos da cadeia produtiva do PVC.

Neste contexto, este trabalho propõe o desenvolvimento de uma metodologia que inclui uma avaliação inicial do estado das empresas participantes em práticas de produção mais limpa e ferramentas de manufatura enxuta através do Benchmarking, criando-se indicadores gerais de avaliação das empresas. Como resposta a esta avaliação surge a ferramenta visual de práticas sustentáveis (FVPS) para a tomada de decisões gerenciais na procura de processos e produtos mais limpos e sustentáveis. Levam-se em conta aspectos intrínsecos da empresa como o time requerido para implantação das práticas, e as ferra- mentas de manufatura enxuta (ME) que possam auxiliar as empresas fabricantes de produtos finais de PVC do estado de Santa Catarina na busca por melhores práticas de manufatura sustentável.

\section{Desdobramento da Metodologia}

Partiu-se da coleta de informações de maneira presencial em 13 empresas do setor de produtos de terceira geração ou produtos finais feitos em PVC, onde foi aplicada a ferramenta "Benchmarking para análise da cultura e maturidade da produção mais limpa" que de forma conjunta com o checklist de manufatura enxuta, resultou num panorama do estado atual das empresas em práticas e performances de produção mais limpa e manufatura enxuta. Foi gerado um relatório comparativo individual e geral das empresas, cuja análise levou à formulação e ponderação de indicadores específicos a fim de interpretar os pontos de caráter prioritário e de atenção direita na tomada de decisões das empresas sobre os aspectos sensíveis a melhoria em cada uma das 13 empresas. 
Figura 1: Panamorama das Empresas através do Benchmarking

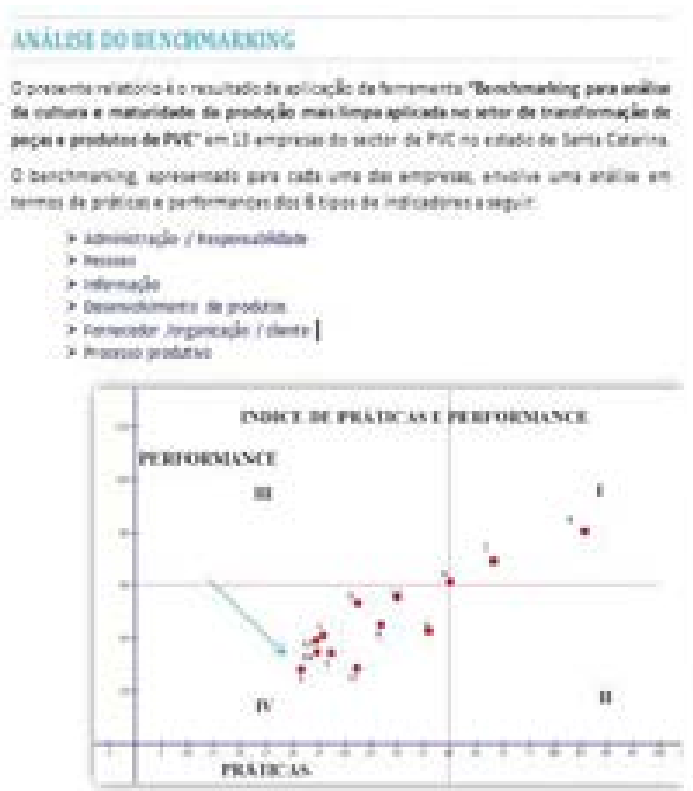

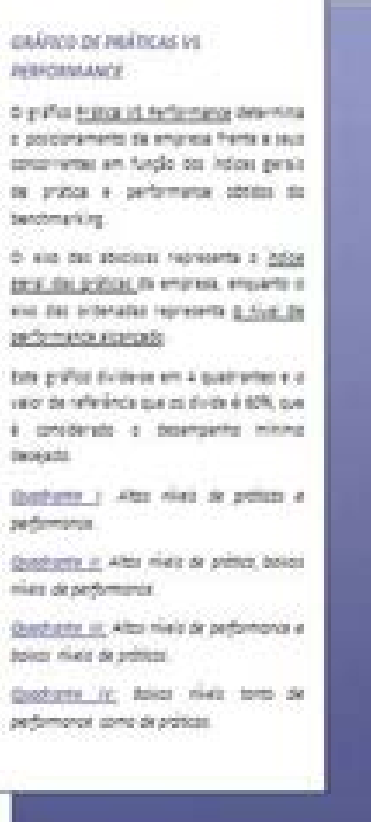

Fonte: Autora 2015

Figura 1: Panamorama das Empresas através do Benchmarking

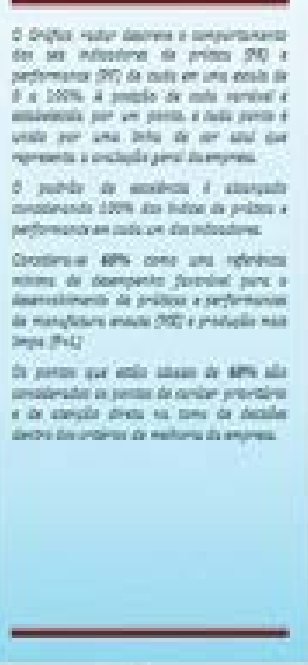

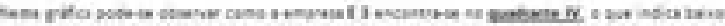

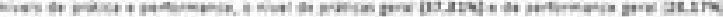

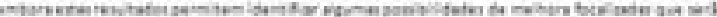

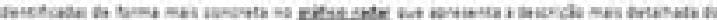
mentis

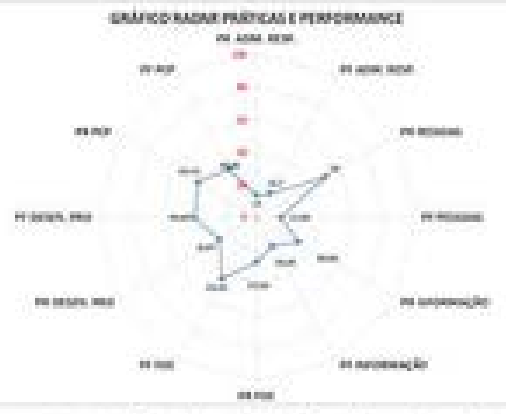

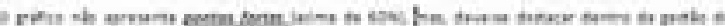

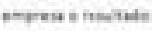

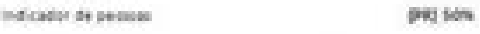

Fonte: Autora 2015 
Na busca de um panorama amplo de práticas que pudessem ser implantadas pelas empresas, criou-se a ferramenta visual de práticas sustentáveis-FVPS que propõe uma grade de 64 práticas, geradas com o intuito de constituir uma ferramenta visual para a tomada de decisões do ponto de vista estratégico e gerencial em termos de sustentabilidade. melhoria em cada uma das 13 empresas.

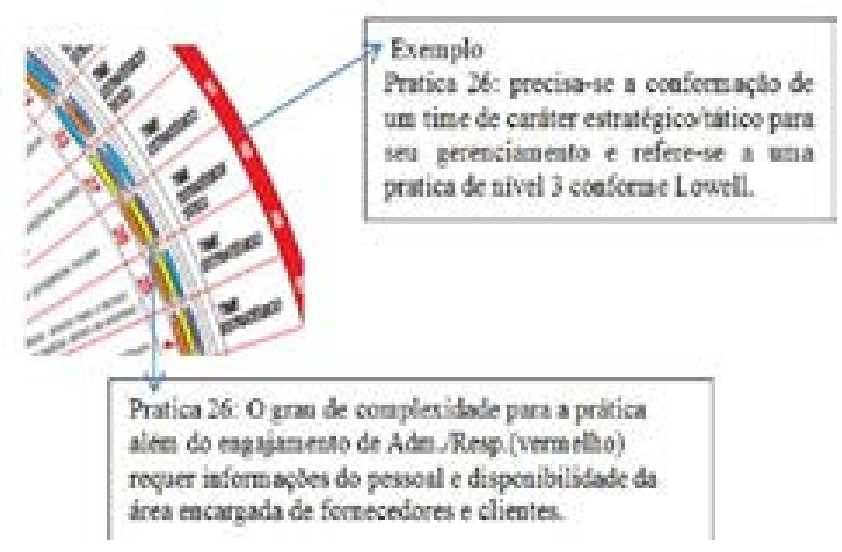

Figura 3: Ferramenta Visual de Práticas Sustentáveis Fonte: Autora 2015

O desenvolvimento, estratificação e estruturação dessa ferramenta, foi construído conforme níveis de relacionamento e interação entre fatores como: grau de investimento, disponibilidade de pessoal, tempo e quantidade de recursos físicos, alocação de materiais e fluxos de informações, aplicando-se critérios de análise hierárquica de processos (AHP), produção mais limpa $(\mathrm{P}+\mathrm{L})$, ferramentas de manufatura enxuta (ME) e metodologias desenvolvidas para a gestão empresarial nos três pilares da sustentabilidade: social, econômico e ambiental.

Entre os resultados obtidos na fase de avaliação geral das empresas em práticas e performance, a média das empresas foi de 48,13\% na avaliação das práticas, e 47,19\% da performance. Encontrou-se a avaliação mais baixa tanto na prática como na performance na variável informação, no quesito da compreensão dos objetivos do processo produtivo para colaboradores externos e internos; isto reflete no desconhecimento das vantagens da implantação da $\mathrm{P}+\mathrm{L}$, e no retorno financeiro que traz ao serem aplicados seus conceitos.

O estabelecimento de indicadores a partir do benchmarking conduz às empresas à que evidenciem e mensurem os quesitos que realmente fazem parte da gestão da empresa, identificando o nível em que a empresa se encontra e os aspectos que precisam ser melhorados

Buscando obter informações não mensuradas, esquecidas ou consideradas não relevantes até o momento. A ferramenta visual de práticas sustentáveis (FVPS) e cada uma das práticas que a compõem, buscam atingir a referência mínima de desenvolvimento sustentável nas empresas além do setor do PVC. Ao possuir uma plataforma comum, mas também flexível, depende intrinsicamente da tomada de decisões gerenciais, levando a organização a estar ciente de seu processo que, de outra forma, conduz a organização à aplicação de ferramentas que não estão alinhadas com os objetivos da organização, e desde o começo não estabelecem uma perspectiva clara da ação a ser realizada conforme a disponibilidade física de implantação o grau de investimento a disponibilidade do pessoal.

Palavras-chave: PVC, Produção Mais Limpa, Manufatura Enxuta, Benchmarking, Manufatura Sustentável, Sustentabilidade.

\section{REFERÊNCIAS}

1. O Ashby, M.F. 2009, “Materials and the environment: eco-informed material choice". Butterworth-Heinemann, Burlington, MA, USA.

2. Azapagic, A. (2003). Systems approach to corporate sustainability: a general management framework. Process Safety and Environmental Protection, 81(5), 303-316.

3. Barbieri, J. C., 2004, "Gestão ambiental empresarial: conceitos, modelos e instrumentos." São Paulo: Saraiva.

4. Bergmiller, G., 2006, “Lean Manufacturers Transcendence to Green Manufacturing: Correlating the Diffusion of Lean and Green Manufacturing Systems", Ph.D. Thesis, University of South Florida.

5. Camp, R.C., 1998, “Global Cases in Benchmarking: Best Practices from Organizations Around the World", Milwaukee: American Society for Quality Control Quality Press.

6. Cinelli. M. , Coles S.R. e Kirwan K., 2014, “Analysis of the potentials of multi criteria decision analysis methods to conduct sustainability assessment", Ecological Indicators, Vol. 46, p. 138-148. 
7. Elias, S., Prata, A., \& Magalhães, L. (2004). "Experiência de implantação da Produção mais Limpa: estudo de múltiplos casos." XXIV Encontro Nacional de Engenharia de Produção, Florianópolis, Santa Catarina.

8. Godinho Filho, M., \& Fernandes, F. C. F. (2004). Manufatura enxuta: uma revisão que classifica e analisa os trabalhos apontando perspectivas de pesquisas futuras. Gestão \& Produção, 11(1), 1-19.

9. Gómez, J.C.O. e Cabrera, J.P.O., 2008, “El proceso de análisis jerárquico (AHP) y la toma de desiciones multicriterio. Ejemplo de aplicación", Scientia et Technica, 2(39), 247-252.

10. Kojima, S., \& Kaplinsky, R. (2004). The use of a lean production index in explaining the transition to global competitiveness: the auto components sector in South Africa. Technovation, 24(3), 199-206

11. LCSP (Lowell Centre for sustainable production), 2011. What is Sustainable Development, disponivel em: http:// www.sustainableproduction.org/proj.SustainableProductslnitiative.php

152 12. Leadbitter, J. (2002). PVC and sustainability. Progress in Polymer Science, 27(10), 2197-2226.

Leadbitter, 2012. Leadbitter J. Personal communication; 2012 